\title{
El pajarete de Huasco y Elqui (Chile). Historia de un vino escogido
}

\author{
Pajarete of Huasco and Elqui (Chile). Story of a selected wine \\ Amalia Castro1, Philippo Pszczólkowski², Fernando Mujica ${ }^{3}$, Pablo Lacoste 4 , \\ Emiliano Núñez ${ }^{4}$, Carolina Cofré4, Michelle L. Adunka ${ }^{4}$, Natalia Soto ${ }^{4}$
}

\section{RESUMEN}

El artículo examina la historia del pajarete, vino escogido de los desiertos del norte de Chile, desde los primeros registros (1790) hasta su reconocimiento como Denominación de Origen y su proyección posterior. El trabajo se fundamenta en documentos como libros de Aduana, la prensa gráfica, los relatos campesinos y los registros de marcas del Instituto Nacional de Propiedad Industrial (INAPI). Se demuestra que el pajarete ha existido durante 225 años en Chile; se ha mantenido como un vino escogido, elaborado, comercializado y consumido en pequeñas cantidades.

Palabras clave: pajarete, vinos escogidos, productos típicos, denominaciones de origen, industria vitivinícola.

\begin{abstract}
The article examines the history of pajarete, a selected wine from the deserts of northern Chile, since records began (1790) up to its recognition as an Appellation of Origin wine and subsequent projection. The paper is based on documents such as customs books, printing press, farmers' stories and trademark registrations. We show that the pajarete wine has existed for 225 years in Chile; it has remained as a chosen wine, which has been developed, marketed and consumed in small amounts.
\end{abstract}

Keywords: pajarete, selected wines, typical products, apellation of origin, wine industry history.

\section{Introducción}

El pajarete es, junto al asoleado, el primer vino chileno reconocido como Denominación de Origen (1953). Se trata de un vino generoso originario del llamado Norte Chico de Chile, particularmente de los valles del Huasco y Elqui. Elaborado por pequeños viticultores artesanales, representa una tradición singular que ha logrado mantenerse viva a lo largo del tiempo, a pesar del avance de las grandes fábricas de vino y los procesos de concentración de la industria.

El estudio del pajarete se entronca con la corriente internacional que se ha interesado en la investigación sobre las Denominaciones de Origen, tanto en Europa como en América. Estos temas han generado una rica bibliografía en los últimos años, como lo reflejan los estudios publicados sobre el
Oporto (Rivero de Almeida, 2010; Bennett, 2005), el Sauternes (Lachaud, 2015), el Rioja (Gómez Urdáñez, 2015; Barco, 2015); entre otros. En América Latina se destacan los estudios sobre las DO en Brasil (Souza, 2015), los estudios del tequila en México, el pisco peruano (Buller, 2011; Huertas, 2012), el singani boliviano (Aillón, 2011; Buitrago, 2014) y el pisco chileno (Jiménez, 2014; Jeffs, 2014; Lacoste et al., 2013, 2014 y 2015).

Dentro de América del Sur, el pajarete no pertenece al grupo de los productos estrella, como el tequila, el pisco o el singani pero sí se ubica dentro del segundo grupo de bebidas relevantes, sobre todo por su temprano reconocimiento como Denominación de Origen. Basta recordar que esta bebida se encuentra entre las primeras DO del Cono Sur, junto al pisco y al asoleado de Cauquenes y Concepción. En ese sentido, el pajarete tiene

\footnotetext{
Universidad Finis Terrae. Santiago de Chile, Chile.

Pontificia Universidad Católica de Chile, Santiago de Chile, Chile.

Escuela Nacional de Sommelier, Santiago de Chile, Chile.

Universidad de Santiago de Chile, Santiago de Chile, Chile.

Autor por correspondencia: pablo.lacoste@usach.cl
}

Fecha de Recepción: 15 Julio, 2015.

Fecha de Aceptación: 15 Mayo, 2016. 
un importante papel simbólico en el proceso de fortalecimiento de la identidad de los productos agroalimentarios chilenos y latinoamericanos en general.

Paradojalmente, el pajarete ha pasado casi desapercibido para la comunidad académica. Muy pocos trabajos se han realizado para estudiar su trayectoria histórica. Algunos autores lo mencionan como producto típico, sin profundizar en sus características (Cortés, 2005). Ello contrasta con otros productos típicos que sí han generado estudios específicos, como el jamón de Chiloé, la chicha (Castro et al., 2016), los vinos de Codpa y Pintatani (Castro, 2015), el queso de Chanco (Aguilera, 2015; Lacoste et al., 2014 y 2015) y el pisco (Cortés, 2005; Jiménez, 2014).

El objetivo del presente artículo es conocer la historia del pajarete a partir de la documentación disponible en los archivos chilenos, principalmente en cuatro corpus documentales: 1) registros de las Aduanas del período tradicional (1790-1850), cuando el pajarete tenía presencia en el comercio de cabotaje chileno; 2) relatos campesinos, particularmente los recogidos en la colección FUCOA; de acuerdo con las normas del Ministerio de Agricultura, este repositorio reúne textos escritos por personas mayores, para reflejar antiguos relatos, originados entre fines del siglo XIX y mediados del XX; 3) medios de prensa locales, incluyendo diarios, revistas y anuarios turísticos, desde el período de surgimiento de las secciones de avisos económicos y clasificados, a mediados del siglo XIX, hasta mediados del XX; 4) registros del Instituto Nacional de Propiedad Industrial (INAPI), desde los primeros registros, realizados a fines del siglo XIX, hasta 1960.

\section{El pajarete y su identidad como vino generoso con Denominación de Origen}

El pajarete es un vino típico del Norte Chico de Chile, reconocido como Denominación de Origen en 1953. Así lo estableció la Ley de Alcoholes y Bebidas Alcohólicas No 11.256, promulgada el 15 de septiembre de 1953 y publicada el 16 de julio de 1954; luego fue modificada por Ley No 17.105 de 1969 y Decreto Ley N 2.753 de 1979 (Errázuriz, 2010).

Las normas de la DO establecen que el pajarete es un vino generoso y genuino producido y envasado en unidades de consumo, en las Regiones III y IV, provenientes de vides plantadas en dichas regiones. En la década de 1980 se utilizaba Uva País para los pajaretes tintos o coloreados; Moscatel de Alejandría, Moscatel de Austria, Torontel y Moscatel Rosado para pajaretes blancos (Sotomayor, 1987). De todos modos, la base vitícola del pajarete ha evolucionado con el tiempo.

En efecto las variedades utilizadas para elaborar el pajarete corresponden a las mismas que se autorizan para el pisco, aun cuando la redacción del decreto (...) "sea más amplia y podría abarcar otras variedades que alguna vez fueron autorizadas para el pisco, como la País y otras. En todo caso, los usos y costumbres establecen que el pajarete no se elabora con uvas de mesa, ampliamente cultivadas en la zona.

Para obtener mayor graduación alcohólica se siguen dos caminos alternativos. Una opción es, previo a la cosecha, comprimir el pedúnculo del racimo, mediante un alicate dejando deshidratarse el racimo en la vid para luego de algunos días a semanas cosecharlo (Gil y Pszczólkowski, 2015). Otra posibilidad es asolear la uva cosechada antes de la fermentación. La cosecha es manual y se emplean métodos tradicionales en todo el proceso, tanto de elaboración como de conservación (Ramírez, 2015).

En los últimos años se han realizado algunos esfuerzos para apoyar a los pequeños productores de pajarete. En 1987 se realizó un Simposio sobre Denominaciones de Origen, en el cual se brindó particular atención al pajarete (Sotomayor, 1987). En 2008 se realizó una alianza entre instituciones estatales, cívicas y académicas (Corfo, Fundación de Innovación Agraria, Universidad de Chile) para asistir a 18 pequeños productores artesanales. A partir de 2010 se comenzaron a ver resultados, con una mejora en los métodos y procesos de producción y distribución, lo que ha despertado promisorias expectativas en el desarrollo de este producto típico (Ramírez, 2015).

La invisibilización del pajarete es parte de una larga tradición entre los tecnócratas chilenos. Por ejemplo Manuel Rojas, en sus manuales de Viticultura y vinificación, se ocupó más de promover la imitación de vinos europeos como Jerez, Oporto, Sauternes y Málaga, antes que de alentar el desarrollo del pajarete chileno (Rojas, 1897 y 1950). La misma actitud asumió Julio Menadier, influyente publicista, editor del Boletín de la Sociedad Nacional de Agricultura. Desde esta posición de poder, Menadier alentaba a los viticultores chilenos a imitar los vinos famosos de Europa, particularmente el Málaga (Menadier, 2012). En el marco del paradigma francés, el principal 
referente de la enología chilena no logró apreciar el valor que podían tener los productos típicos del Norte Chico. En lugar de destacar el significado de la innovación y de la creación original, estos intelectuales alentaron la cultura de la imitación.

\section{El pajarete como producto típico: entre España y Chile}

El pajarete chileno es un producto típico vinculado a su homónimo español. Se trata de un caso parecido al Chacolí: los colonizadores españoles asentados en Chile durante el período imperial, procuraron elaborar un producto que evocara al que habían conocido en la península. En el norte de España, los vascos desarrollaron el Chacolí (Barreda, 2001; Hidalgo et al., 2012) у sobre esa base, nació el chacolí chileno (Lacoste et al., 2015). En el sur de la península, los andaluces desarrollaron diversas bebidas típicas, como Jerez, Pedro Ximénez y pajarete. El pajarete español gozó de prestigio en los siglos XVIII y XIX; su precio de mercado era superior al Jerez y obtuvo siete medallas de oro en la Exposición Universal de París (1889); pero la plaga de filoxera destruyó los viñedos que lo sustentaban y, a partir de entonces, quedó acotado a un producto de consumo local (Rivero et al., 2001). Sobre la base de esta tradición, los colonizadores españoles desarrollaron en Chile el pajarete local.

El pajarete español es un vino generoso, que adoptó su nombre del lugar de origen: Pajarete, localidad de Jerez de la Frontera. Se caracterizaba por tener una graduación alcohólica que oscilaba entre $15^{\circ}$ y $20^{\circ}$. Para alcanzar esta graduación se implementaban diversos métodos, pero el más natural era asolear la uva después de la cosecha, de modo tal de obtener mayor concentración de azúcar mediante deshidratación natural. Dentro de la clasificación local de los vinos de Jerez de la Frontera, el pajarete, junto al apagado, Moscatel y Pedro Ximénez, pertenecía a los vinos dulces de un conjunto mayor signado como vinos naturales (Abela, 2008).

El surgimiento de los vinos dulces españoles se produjo en un contexto mayor, de escala continental, marcado por la demanda de vinos de los países del norte de Europa hacia las naciones del sur, favorecidas por los climas para el cultivo de la viña (Braudel, 1994). A medida que se consolidaban los estados nacionales, se vigorizó el comercio y la posibilidad de desarrollar nuevos mercados. En el caso del vino, había problemas técnicos para mantener la calidad del producto en viajes largos; en ese sentido, los vinos dulces y con mayor graduación alcohólica ofrecían la ventaja de mejor capacidad de mantener la calidad a pesar de las travesías. "Los vinos dulces con un elevado contenido alcohólico duraban más que los vinos secos ligeros, y parece ser que a finales del siglo XVI los productores españoles también estaban tratando de envejecer sus vinos" (Unwin, 2001). En el extremo oriental de Imperio español de los Habsburgo, particularmente en Hungría, por el mismo período despuntaba el vino dulce llamado Tokay, famoso en toda Europa (Unwin, 2001). Junto con la mejor transportabilidad, había razones de mercado que tendían a favorecer este tipo de vinos: "Grandes clientes, bebedores no siempre experimentados pero exigentes, que preferían por lo general vinos de muchos grados: así por ejemplo, los ingleses dieron fama, muy pronto, a las malvasías, vinos dulces de Candia y de las islas griegas. Pusieron de moda después los vinos de Oporto, de Málaga, de Madeira, de Jerez y Marsala, vinos célebres, con muchos grados" (Braudel, 1994).

La construcción del prestigio de estos vinos típicos en los mercados, fue un proceso largo y complejo, en el cual influyeron distintos factores. "Hasta el siglo XVIII, la fama de los grandes vinos tarda en afirmarse. El hecho de que algunos sean más conocidos se debe no tanto a sus propias cualidades como a la comodidad de su transporte y, sobre todo, a la proximidad de las vías fluviales o marítimas (Braudel, 1994). En el caso de la Península Ibérica, la posición estratégica de los productores del río Duero facilitó la difusión del Oporto; en Francia, el puerto de Burdeos, sobre el Atlántico, fue una ventaja comparativa importante; y lo mismo ocurrió en Andalucía con los productores de Jerez, que tenían facilidades para sacar sus vinos por vías fluviales y marítimas.

Los vinos especiales españoles encontraron buenos mercados en el norte. La demanda de los nobles de Gran Bretaña, Francia, Holanda, Finlandia y otros países, contribuyó a alentar la elaboración de vinos dulces. En Francia, durante el siglo XVIII, la nobleza prefería algunos vinos dulces y generosos andaluces, como los de Rota, Jerez y Málaga. Además de estos figuraba el pajarete. Así, por ejemplo, "en 1793, 71 botellas de málaga, 170 de jerez y cuatro de pajarete se encontraron en la bodega del obispo de Évreux" (Duhart, 2010). Igualmente se detectaron, en 1782, pajaretes en la bodega del duque de Aiguillon, y dos años antes, en 
las cavas de Toussaint Le Long habían 33 botellas del vino generoso (Duhart, 2010).

En la segunda mitad del siglo XVIII, los vinos andaluces estuvieron en el centro de la moda francesa, constituían atributos del buen gusto. "En el capítulo del Tableau de Paris que dedicó a los vinos escogidos, Louis Sébastien Mercier evocó el perfume del vino de Rota, del pajarete, del Málaga y del Moscatel de Málaga antes de llegar a la conclusión que estos néctares deberían abrevar la inspiración de los poetas en vez de ser consumidos por gourmets ricos e incapaces de apreciarlos correctamente" (Duhart, 2010). A finales del siglo XIX, y a pesar de catalogarlo de una calidad inferior al Jerez, Alejandro Dumas, en su obra "De Paris a Cádiz", plasma el comercio del pajarete en Sanlúcar entre los viajeros que van de Santa María a Cádiz (Lacoste y Duhart, 2010). Para este época, el pajarete también figuraba en banquetes celebrados en honor del emperador Guillermo II de Alemania (Ramos Santana, 2004).

Es importante señalar que estos vinos no se consumían durante las comidas, sino antes o después de las mismas. Por lo general, los vinos dulces se servían de postre. "Los vinos andaluces y los caldos más corrientes o de menor graduación alcohólica no se tomaban de la misma manera. Las botellas de vinos generosos entraban en escena al fin de la comida, en número reducido. En junio de 1770, por ejemplo, los frascos de pajarete y de Málaga representaron solo un 7,6\% del número total de botellas de vino compradas con motivo de una fiesta ofrecida por los cónsules de Toulouse a una personalidad local" (Duhart, 2010).

A pesar de su pequeño nicho de mercado, los vinos dulces en general, y el pajarete en particular, lograron un desarrollo económico relevante en la época. Hacia fines del siglo XIX, en España, los vinos generosos alcanzaban altos precios en comparación a sus pares. Este costaba 150 pesetas el hectolitro, frente al el tinto común, el de Cataluña, el vino blanco y el de Málaga, cuyo valor era de 35, 50, 60 y 90 pesetas, respectivamente. Solo era superado por los vinos de Jerez y Sanlúcar (200 pesetas el hectolitro). En Jerez, la botella de pajarete superior costaba 5 pesetas y la caja de 24 unidades 120 pesetas (Abela, 2008). Su mayor precio estaba justificado por su más sofisticada elaboración.

La cultura de la valoración de los vinos especiales como el pajarete, viajó de España a América en los barcos de los colonizadores. Una vez en el terreno, las condiciones de climas y suelos que encontraron en el norte de Chile, sobre todo en los valles del Huasco y el Elqui, inclinó a los colonos a buscar la forma de elaborar vinos de más alta calidad, aprovechando las cualidades de las variedades de uva locales, para lograr productos especiales. En efecto, las viñas se arraigaron satisfactoriamente en dichos valles en la segunda mitad del siglo XVI. Y a partir de la centuria siguiente se generaron buenas condiciones para obtener vinos especiales, sobre todo a partir de la llegada del Moscatel de Alejandría, a comienzos del siglo XVIII. A partir de entonces se generaron las condiciones para poner en marcha un vino especial, dulce y de alta graduación alcohólica: el pajarete chileno.

\section{Pajarete en el comercio chileno: los registros de Aduanas}

El registro más antiguo detectado hasta ahora del pajarete en Chile data del 25 de agosto de 1790. Se trata de una partida de cuatro docenas de botellas de pajarete (llamadas limetas) que se embarcaron en el Águila, mercante que servía la ruta de El Callao a Coquimbo y Valparaíso. El objeto de esta partida de pajarete no era el comercio sino el abastecimiento de la tripulación durante el viaje (rancho). Con el mismo fin se registraron otras bebidas y alimentos típicos, incluyendo tres barriles de vino de Penco, ocho docenas de lenguas de Chile y como veinte jamones, seguramente de Chiloé (Archivo Nacional, Contaduría Mayor, serie 1, Aduana de Coquimbo, volumen 1715). Al parecer, el plan era utilizar el vino de los barriles para los marineros y el pajarete para los oficiales.

El pajarete era apreciado como bebida de calidad superior y por este motivo fue una de los primeros vinos envasado en botellas, producto muy escaso en el siglo XVIII en el sur de América. Mientras los vinos de consumo corriente se distribuían en botijas o barriles, el pajarete se guardaba en botellas. Y solo aparecía en cantidades acotadas. Así se reflejó también en los registros de la Aduana de Chiloé, donde se detectaron dos partidas de pajarete en la década de 1840. En efecto, el 15 de mayo de 1843, la Aduana de Chiloé registró el desembarco de una partida de doce botellas de pajarete, llegadas a bordo de la barca nacional Guillermo (Archivo Nacional, Tesorería y Aduana de Chiloé, volumen 67). Poco más tarde, el 14 de enero de 1847 , se documentó otro cargamento de doce botellas de pajarete desembarcado para su 
venta en Chiloé, en la barca nacional Valparaíso. (Archivo Nacional, Tesorería y Aduana de Chiloé, volumen 61, documento 68).

Los registros de aduana muestran datos de interés. En primer lugar, aportan pruebas documentales de la presencia del pajarete en Chile entre fines del siglo XVIII y mediados del XIX. Segundo, destacan la exclusividad de la botella como envase del pajarete; y tercero, muestran como patrón, la costumbre de difundir el pajarete en pequeñas cantidades, como vino escogido para ocasiones especiales y reservado para las élites.

\section{El pajarete en los relatos campesinos}

La tradición del pajarete se ha mantenido presente en la memoria colectiva del pueblo chileno, tal como se refleja en los relatos campesinos de la colección FUCOA. Como se ha señalado este repositorio reúne textos que se han transmitido en forma oral, de una generación a otra, por medio de las narraciones de abuelos a nietos alrededor de chimeneas y fogones. Dentro de este contexto, los relatos campesinos han incluido referencias al pajarete, lo cual contribuye a su apreciación dentro del patrimonio intangible del país. Un buen ejemplo se halla en el cuento "La Vendimia en el valle del Carmen", escrito por una vecina de Vallenar, Región de Atacama (Olmedo, 2007).

El relato de Olmedo entrega un conjunto de claves para identificar los cuatro elementos fundamentales que, para la cultura campesina, definen el paisaje dentro del cual se elabora el pajarete: tierra, agua, sol y clima, cada uno de los cuales, tiene sus propios atributos. La tierra es "bendita y generosa"; el agua se caracteriza como "pura", enfatizando que "baja del cordón cordillerano"; el sol es intenso y el clima, privilegiado. Sobre la base de estos cuatro pilares, se elaboraba el pajarete.

Dentro de los cultivos de los oasis regionales se considera que el lugar más destacado corresponde a la uva. La autora destaca el perfil tradicional de los cultivos. Señala, por ejemplo, el uso de árboles vivos como medios de sostén de las parras, como aún hoy se observa en los valles de Cotagaita y Tumusla, Departamento de Potosí, Bolivia. Estas no se cultivaban en espalderas ni extensos parrales, como se había impuesto en casi todo Chile a partir del desembarco del paradigma francés, a mediados del siglo XIX. Al contrario, los pequeños productores artesanales de los oasis del Norte Chico, conservaban todavía los métodos más tradicionales de cultivo de la vid, a la usanza de Europa Medieval, en un diálogo de armonía con el medio ambiente.

Además del método de cultivo, el relato de Olmedo destacaba también las variedades de uva utilizadas para elaborar el pajarete. Dentro de este tema, la autora destaca la persistencia de las variedades históricas, tanto las que trajeron los españoles como las criollas que nacieron en la región. En efecto, el relato enfatiza la presencia de Uva País y Uva de Italia (Moscatel de Alejandría), variedades que llegaron con los colonizadores al Norte Chico de Chile en los siglos XVI y XVIII respectivamente. También destaca las variedades criollas, surgidas del mestizaje entre las dos anteriores, como la Uva Pastilla (Moscatel Rosada) y "Moscatel de Austria" (Torrontés Sanjuanino). La autora menciona también la uva "Ardilla", tal vez con intención de referirse a la llamada Albilla, otra variedad criolla de acotado desarrollo en Chile. Con notable claridad conceptual, y palabras sencillas, la voz de esta campesina explicaba el lazo entre las variedades tradicionales de la uva, y la identidad del pajarete: "por la gran cantidad de azúcar que contiene la uva tenemos el famoso vino dulce llamado pajarete" (Olmedo, 2007).

La percepción de la campesina sobre la esencia del pajarete se decanta en el entorno ambiental y cultural. Olmedo destaca el carácter casi silvestre de la Uva País; también enfatiza el impacto que produce la visión de sus raíces, desnudas, aferradas al suelo rocoso. La fuerza de esta imagen se conjuga con los sarmientos que se aferran, silvestres, a los troncos de los árboles. Y como remate, se evocan prácticas tradicionales, como la pisada de la uva en lagares de cuero de cabra. El relato logra integrar, en sencillas palabras, una esencia modelada durante siglos de historia y cultura.

\section{Pajarete en el INAPI: registros de Marcas}

$\mathrm{El}$ ingreso aluvial de bebidas importadas en la segunda mitad del siglo XIX planteó un brusco cambio en los mercados de vinos escogidos en Chile. Sobre todo porque las élites nacionales fueron seducidas por la magia de los productos europeos, que les ofrecían la posibilidad de diferenciarse del pueblo y mostrar un gusto refinado y exclusivo. Chile se convirtió en atractivo mercado para los productos de lujo importados desde Europa. La Estadística Comercial de Chile registró el ingreso de 
notables cantidades de Jerez, Oporto, Champagne y Sauterne (Couyoumdjian, 2006). Muchos de estos productos ingresaban al mercado nacional dentro del nicho de los vinos especiales, para satisfacer la demanda de las élites, lo cual significaba desplazar directamente al pajarete. Se avanzó entonces en un proceso de sustitución de producción interna de alto valor agregado por bebidas importadas, en un marco de desindustrialización y desnacionalización de la economía.

El constante flujo de los vinos especiales importados se potenció con las campañas publicitarias financiadas por las grandes casas de comercio, muchas de ellas extranjeras, que tendían a sobrevalorar las bebidas extranjeras e invisibilizar los productos típicos nacionales. Ello se sumó a las modas que adoptaron las élites chilenas en el sentido de priorizar y valorizar el consumo de bienes europeos como mecanismo de distinción social. Como resultado, se estimuló el consumo de Jerez, Oporto y Málaga, en detrimento de los vinos típicos chilenos como el pajarete. Todo ello se reflejó en los registros de la época, mediante los cuales se puede conocer el proceso con mayor detalle.

Para la presente investigación se han examinado los archivos del INAPI para indagar la existencia de marcas de pajarete. Se han compulsado los volúmenes disponibles desde el inicio de los registros, a fines del siglo XIX, hasta la fecha de delimitación del pajarete como Denominación de Origen (1953). Dentro de este lapso, muy pocas empresas se interesaron por registrar marcas de pajarete, lo que muestra el escaso desarrollo comercial alcanzado por el producto. De todos modos hubo siete casos interesantes registrados por tres empresas privadas y una cooperativa.

Los empresarios interesados en registrar marcas de pajarete fueron 1) Juan Terrisse, 2) Evaristo Guerrero Alday, 3) Florencio Flores y Juan Zepeda; 4) Manuel Gómez, y 5) "Sucesión Agustín Barraza" (sin mencionar un titular individual). Juan Terrisse asentó su producto en 1934 y 1945. La Sucesión Agustín Barraza lo hizo en 1946. Por su parte, Guerrero Alday protocolizó su marca en 1951. Florencio Flores y Juan Zepeda inscribieron su vino pajarete en 1953; finalmente, en 1955, es decir, posterior a la entrada en vigencia de la DO, realizó su registro el comerciante Manuel Gómez. A ello se sumó la "Sociedad Cooperativa Agrícola Control Pisquero de Elqui" y "Vitivinícola del Norte Limitada", que registró la marca en 1948.
La primera etiqueta de pajarete fue la registrada por Terrise en 1934. Se trata de "Pajarete del Huasco" de Juan F. Terrisse. El marbete se presenta en dos colores, con letras doradas sobre fondo negro. Como ilustración se apela a un retrato del siglo XVIII, con peluca a la moda, para representar una idea de antigüedad y abolengo del producto. La empresa comercializó el pajarete durante más de una década, pero fue cambiando la marca y la simbología. En el nuevo registro presentado en 1945, se reivindica la marca "Esfinge" y se cambia el dibujo del ilustrado dieciochesco colonial por una efigie egipcia. Se

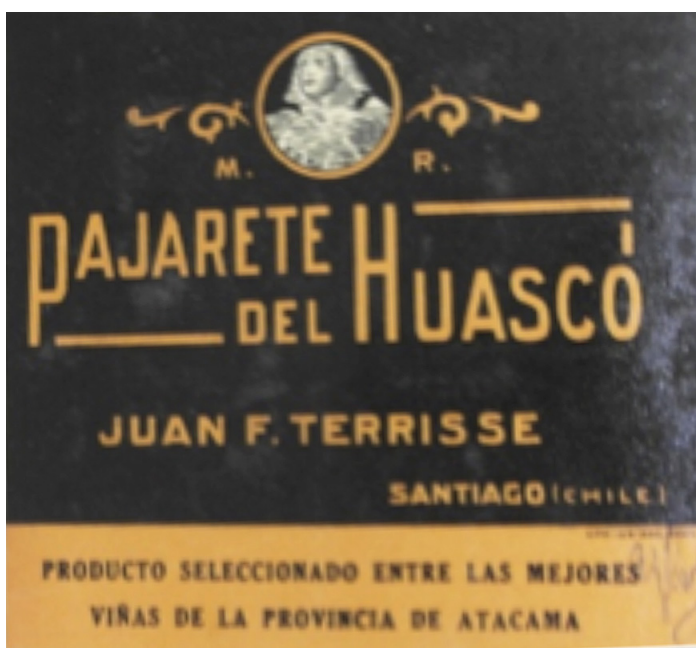

Figura 1. Pajarete del Huasco "Juan Terrisse” (INAPI, 1934).

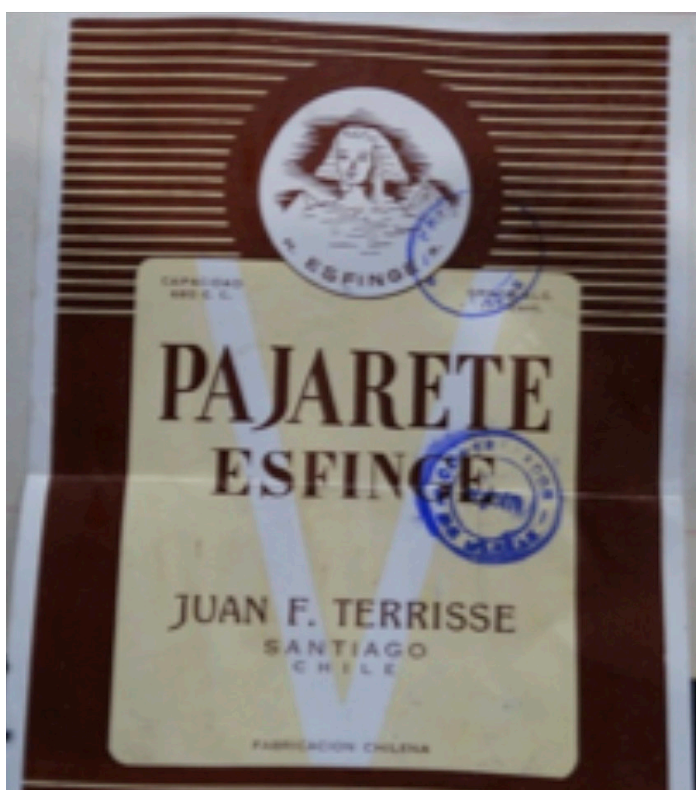

Figura 2. Pajarete Esfinge "Juan Terrisse” (INAPI, 1945). 
abandonan los valores del arraigo histórico local, para apelar al exotismo.

En 1946 encontramos un nuevo registro de pajarete a nombre de "Sucesión Agustín Barraza". Vale la pena mencionar que lo que parece a primera vista una denominación provisoria a efectos jurídicos ("sucesión"), es en realidad el nombre comercial de la empresa: no solo figura a efectos legales en el registro, también aparece en la etiqueta del producto. A diferencia del exotismo de Terrisse, esta etiqueta toma el camino opuesto y alude a un elemento típico del paisaje vitivinícola: se observa una vid que "trepa" por la etiqueta y funciona a la vez como marco en el diseño de la misma. Debajo del nombre comercial y el anagrama, se destaca, en letras más grandes que el resto, el fundo local del cual proviene el producto. Este elemento local se refuerza por la triple mención a "Atacama, Vallenar, Huasco Alto". Por otro lado, esta etiqueta presenta una característica que la hace única entre las cinco halladas en el INAPI: la referencia a premios ganados por el producto en cuestión. Las menciones a los mismos se encuentran divididas por su procedencia geográfica. Debajo de "pajarete" se ubica el "Primer Premio Exposición de Peñuelas". En un apartado distinto se ubican los premios internacionales: "Medalla de Oro Exposición de Bolivia" y "Medalla de Plata Exposición de Sevilla". No deja de ser paradójico que, para conquistar la preferencia del consumidor, el producto local debía obtener premios en Europa. Otro detalle de este diseño es la representación de una cepa que trepa por la etiqueta lo mismo que los cultivos tradicionales relatados por la campesina Olmedo (2007).

En la misma línea que la etiqueta anterior, la Cooperativa Control apostaba por la reivindicación

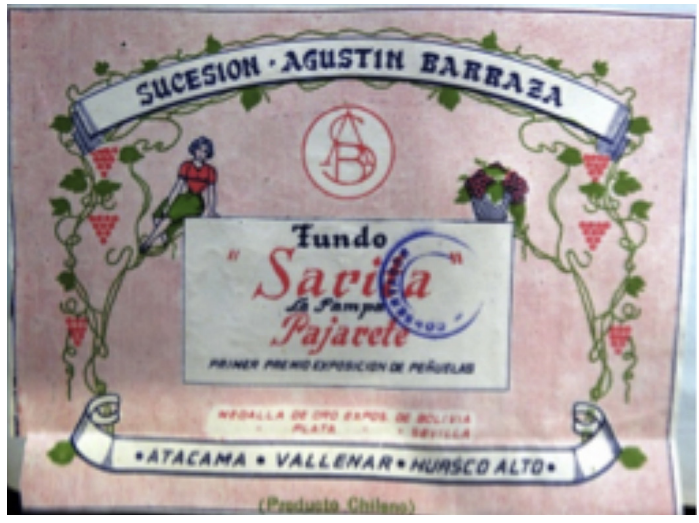

Figura 3. Pajarete - Fundo Sarita - "Sucesión Agustín Barraza", (INAPI, 1946). local del producto. En efecto, esta empresa tomó la decisión de comercializar el pajarete a partir de la identidad regional, tomando como emblema el concepto "Pajarete del Huasco", justamente el que su competidor privado estaba deshechando.

La Cooperativa Control fue un espacio particularmente relevante para el desarrollo del pajarete en esos años. Al parecer, hubo cierta sintonía filosófica entre la naturaleza del pajarete, como producto típico elaborado en forma colectiva por la comunidad regional, y la cooperativa, como empresa construida en forma solidaria entre pequeños productores locales. La Cooperativa Control Pisquero se dedicó durante varios años a envasar el pajarete elaborado en la región, para luego distribuirlo en los mercados a través de sus redes. Por ejemplo, en 1944, la Cooperativa Control envasó y distribuyó 36.000 litros de pajarete elaborados en la destilería Horcón Quemado, ubicada en el río El Carmen (Sotomayor, 1987).

Esta empresa impulsó la cultura de la apreciación de las Denominaciones de Origen: basta señalar que esta etiqueta se registró en 1948 , señalando que el pajarete tenía "Derecho a Denominacion de Origen", varios años antes que efectivamente, el Estado reconociera y delimitara la DO pajarete. En cierta forma, los productores de pajarete tomaron el riesgo de impulsar el cambio, con el diseño y registro de esta etiqueta. Este marbete refleja la voluntad de los pequeños productores organizados en la Cooperativa Control, y su decisión de dar una batalla que se pretendía ganar: luego de una afirmación de esa naturaleza, no hay alternativa, no se trata de un producto condenado a desaparecer. Por "derecho propio", el pajarete tenía que abrirse camino.

Paralelamente, otras iniciativas se desarrollaron en torno al pajarete. El proceso se completó con la cuarta etiqueta, registrada por Guerrero Alday. En esta

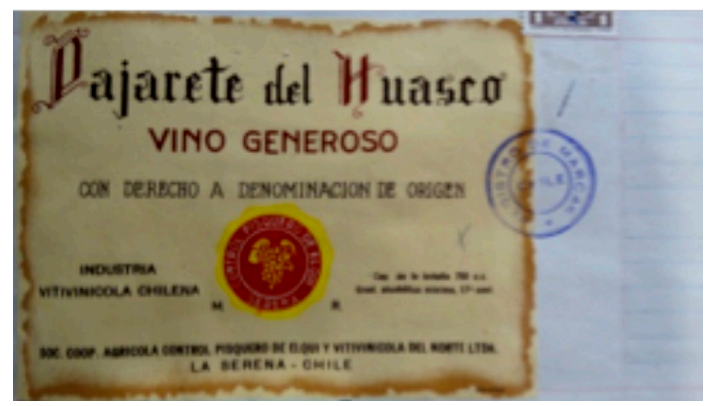

Figura 4. Pajarete del Huasco - Vino Generoso Control (INAPI, 1948). 
se consolida la afirmación de la identidad territorial, destacando localidades geográficas del norte, con los conceptos de "Atacama", "Vallenar" y "Huasco Alto". Se apela también al productor como garantía de calidad, particularmente el nombre específico del lugar de elaboración (Fundo El Pedregal).

El desarrollo comercial del pajarete fue un esfuerzo considerable de los pequeños productores locales, que no logró abrirse camino satisfactoriamente en los mercados. A este producto se le dificultó prosperar en espacios dominados cada vez más por los grandes comerciantes, que disponían de grandes capitales para financiar campañas de marketing a través de los medios masivos de comunicación y del control de las cadenas de distribución. Las notables asimetrías entre los grandes capitales comerciales y los pequeños productores artesanales de pajarete no pudieron ser equilibradas por el esfuerzo ni por la creatividad de sus protagonistas. Era indispensable el papel del Estado para mitigar esas asimetrías.

\section{Pajarete y campañas publicitarias a través de la prensa}

El pajarete también se promovió por medio de campañas publicitarias difundidas mediante la prensa gráfica de la época. Así se reflejó, por ejemplo, en los avisos comerciales publicados en los periódicos chilenos entre mediados del siglo XIX y mediados del XX. Evidentemente, este producto típico no tenía detrás grandes empresas con capacidad de contratar campañas costosas de promoción. Siempre estuvo asociado a pequeños productores y su capacidad de disponer de capitales para financiar la publicidad

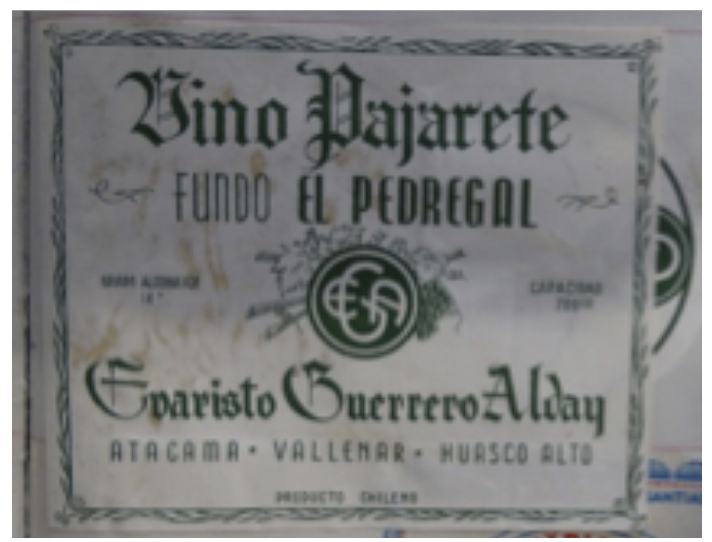

Figura 5. Pajarete "El Pedregal" (1951). era muy limitada. De todos modos estuvo presente en los medios.

Los avisos de pajarete fueron publicados en el diario El Ferrocarril y en la revista En Viaje, ambos editados en Santiago de Chile. El primero fue, en la segunda mitad del siglo XIX, el diario comercial por excelencia que circuló en Chile. En ese tiempo se editaron también otros periódicos con noticias; pero ninguna logró disputarle el liderazgo en el campo de los avisos clasificados y económicos. $E l$ Ferrocarril fue el principal referente para la actividad comercial del país durante ese largo período.

Hacia mediados del siglo XIX, el pajarete estuvo presente en la sección de avisos económicos del diario El Ferrocarril en dos oportunidades: 22 de febrero y 8 de septiembre de 1858. (ver Figuras 6 y 7). En ambos casos la mención de este producto se efectuó en mensajes diferentes, cada uno de los cuales, entrega información de interés.

El primero de los avisos consiste en un anuncio de remate. La idea era promover la venta de licores, juntamente con carruajes y artículos de mercería.
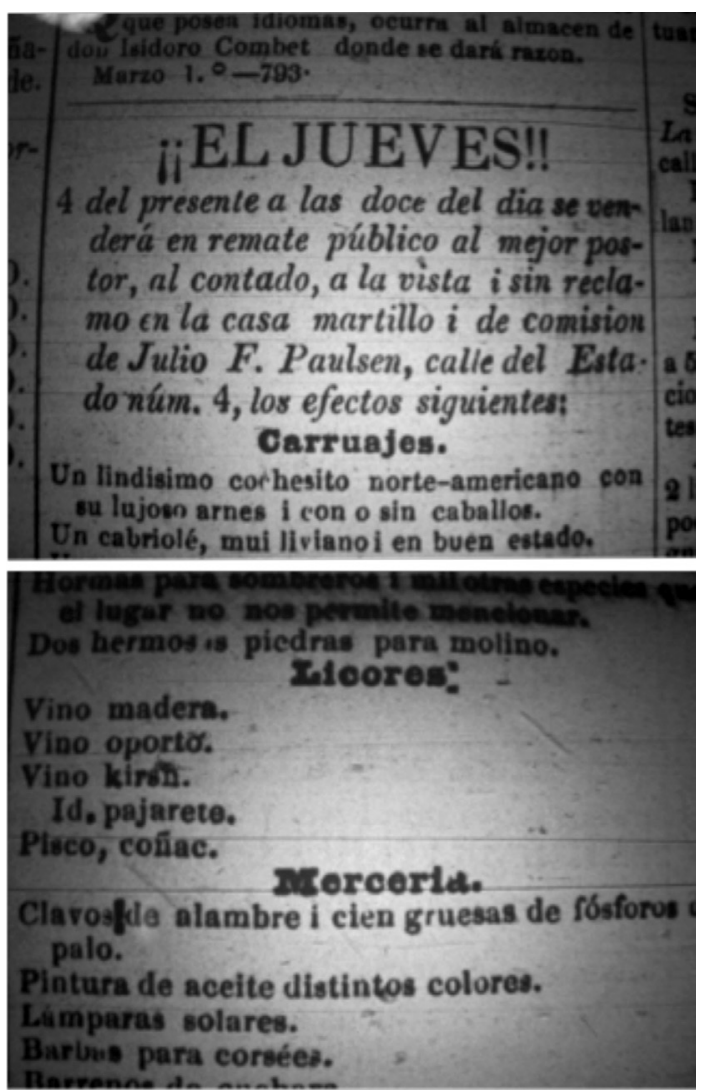

Figura 6. El Ferrocarril , Santiago de Chile, 22 de febrero de 1858. 


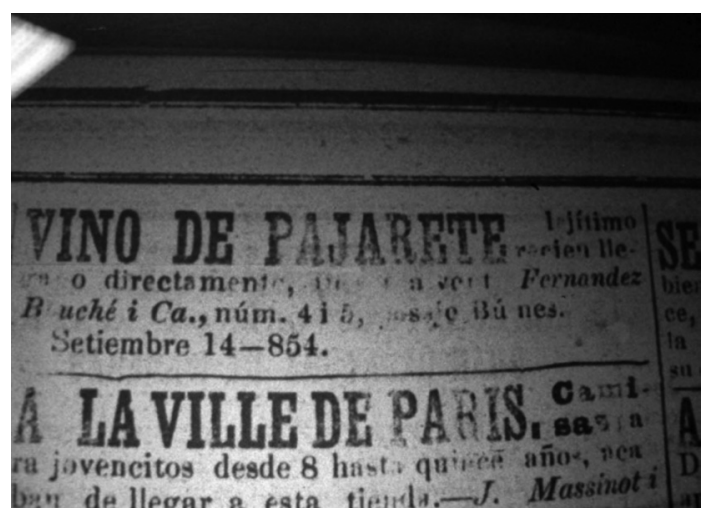

Figura 7. El Ferrocarril, Santiago de Chile, 8 de septiembre de 1858.

Entre las bebidas alcohólicas en venta, se incluían vinos de Oporto, madera y pajarete, juntamente con pisco y cognac. Es interesante el documento porque muestra el contexto dentro del cual se situaba el pajarete: se ubicaba dentro de un conjunto de vinos y aguardientes especiales y de alto valor de mercado. Basta recordar que el vino de Oporto ya estaba delimitado como Denominación de Origen desde 1759 por el marqués de Pombal, mientras que el cognac lograría el mismo reconocimiento en 1909 y el pisco en 1931. Pues bien, dentro de este selecto conjunto de bebidas escogidas se encontraba justamente el pajarete.

El segundo aviso se publicó siete meses más tarde, en vísperas de las fiestas patrias de Chile, en septiembre. En este caso, el anuncio se focaliza exclusivamente en este vino especial y no en otros artículos. Además, el concepto "pajarete" aparece con letras de mayor tamaño y en negritas. El texto enfatiza que los vinos allí ofrecidos eran legítimos, lo que implícitamente muestra que en ese tiempo el pajarete era un vino prestigioso, que había despertado la codicia de los comerciantes inescrupulosos que trataban de lucrar con su fama mediante falsificaciones.

En las décadas posteriores, la tradición de elaboración y distribución del pajarete se mantuvo dentro de un perfil bajo, a escala artesanal, sin campañas significativas en los medios de prensa de la época. Para la presente investigación se revisaron diversos periódicos, incluyendo $E l$ Mercurio de Valparaíso, El Mercurio de Santiago, El Diario Ilustrado, El Comercio de San Felipe, El Coquimbo de la ciudad homónima, y otros diarios, sin poderse encontrar anuncios de pajarete en sus páginas. $\mathrm{Al}$ parecer, los productores optaron por mantener un perfil bajo. El nombre histórico de pajarete se invisivilizó. En su lugar, se promovió el "vino generoso del Huasco". Así se reflejó en avisos publicados en El Diario Ilustrado entre 1905 y 1907. Particular presencia tuvo el vino generoso del Huasco, de V. Feydieu Vallade, distribuido en Santiago desde la bodega "San Martin", situada en calle San Isidro 88. Por medio de los avisos clasificados la empresa ofrecía dos productos: el vino "especial" y "superior" de seis años, y el vino "reservado" de 10 años. Se vendía por litros o por botellas; también se ofrecía en botellas doradas; estas contenían vino añejo dulce, "especialmente escogido para enfermos". Como argumento publicitario, los anuncios sostenían que este vino era "el mejor conocido en plaza"; también se sostenía que "no tiene rival" (El Diario Ilustrado, 30 de abril de 1905 y 1 de mayo de 1905). Dos años más tarde, volvieron a aparecer anuncios para promover el vino generoso del Huasco. No se mencionaban marcas, pero se insistía en sus cualidades "para enfermos y ancianos". El punto de distribución estaba en el centro de Santiago, cerca del lugar anterior, en calle Merced 286 (El Diario Ilustrado, 11 de octubre de 1907). Estos avisos demostraron la persistencia de los viticultores del Huasco en la elaboración de sus vinos especiales. No utilizaron el nombre de pajarete, pero mantuvieron viva la tradición regional. La invisibilización del concepto de pajarete se mantuvo durante un largo tiempo. Recién volvió a hallarse referencia a este producto en 1943 en las páginas de la revista En Viaje.

En Viaje era una revista editada por la empresa de Ferrocarriles del Estado de Chile con frecuencia mensual, en el segundo tercio del siglo XX. Un aviso de pajarete se publicó en el número 116 de esta revista, correspondiente a junio de 1943, a un tamaño de un octavo de página. El aviso fue ordenado precisamente por Evaristo Guerrero Alday, cuyo registro de marca ya se ha mencionado (vid ut supra). El anuncio comercial mencionaba la "Viña del Río San Félix". Se presentaba como "especialidad en pajarete del Huasco". Resulta interesante constatar que el anuncio se dedicaba exclusivamente a promover este producto (Figura 8).

La presencia del pajarete entre los avisos económicos y clasificados de la prensa chilena sirve para mostrar la persistencia de su producción, y su bajo perfil. Entre mediados del siglo XIX y mediados del XX, apenas se realizaron avisos para promover la venta y consumo de este producto. No 


\section{Evaristo Guerrero A.} VIÑA DEL RIO SAN FELIX

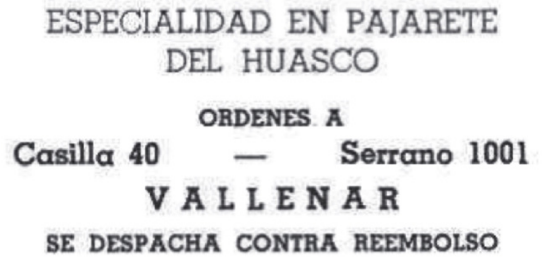

Figura 8. Publicidad del pajarete de Evaristo Guerrero Alday. Revista En Viaje No 116 (Santiago de Chile), junio de 1943.

se detectaron campañas masivas, como sí ocurría con otros tipos de bebidas, sobre todo extranjeras o los vinos nacionales de las grandes empresas. El pajarete, en cambio, mantuvo siempre su perfil artesanal, propio de vinos escogidos, en manos de pequeños productores, que apenas tenían alguna presencia pública a través de los medios.

Hacia mediados del siglo XX, las campañas de promoción del pajarete se reorientó de los diarios y revistas, a las guías de turismo. Estas eran publicaciones anuales editadas por la empresa de Ferrocarriles del Estado, para promover el patrimonio y el turismo de Chile, incluyendo sus paisajes y gastronomía. Los anuncios dedicados al Huasco y al Valle del Elqui coincidieron en destacar los productos típicos de estas localidades, particularmente los vinos generosos y el pajarete.

La presencia de estos vinos se celebraba como parte de los argumentos para visitar Vallenar, capital del departamento del Huasco. "Hay excelentes vinos dulces, pisco e industrias de frutas secas muy apetecidas en el país entero y aun en el exterior" (EFE, 1945). También se destacaban como atractivo turístico, pasas del Huasco, pajaretes y pisco (EFE, 1956). En otra publicación se enfatizaba "la delicia de las pasas del Huasco" y "el pajarete de Vallenar" (EFE, 1959). Este relato se renovaba en la década siguiente, con palabras parecidas, destacando los valles de Copiapó, Huasco y Freirina por ser "zona famosa por su producción de pisco, aguardiente y pajarete" (EFE, 1966). Para 1970, la Guía General de Chile destacaba la vitivinicultura de Vallenar. "Los viñedos regionales producen el vino conocido como 'pajarete', muy afamado en todo el país, como también piscos de excelente calidad. La vendimia de esta región da origen a pintorescas fiestas de carácter folklórico" (INUPAL, 1970).
El protagonismo de los productos típicos dentro de la oferta turística de los valles de la región de Atacama, se destacaba también en el valle del Elqui. En 1956 se invitaba a conocer el fundo Los Nichos, "pequeños recintos en donde se conservan vinos añejos que datan de más de cien años, generosos caldos que tienen un bien merecido y ganado prestigio en el país y en el extranjero" (EFE, 1956). Tres lustros después, persistía la valoración del valle del Elqui como espacio dotado de vinos y licores especiales: "es característico por sus viñedos, de los que se obtienen los afamados piscos de Elqui, vinos, añejos y pasas" (INUPAL, 1970).

Entre 1945 y 1970, las guías turísticas editadas en Chile, identificaron el pajarete y los vinos generosos de los valles del Huasco y del Elqui, entre los principales atractivos turísticos de esas regiones. Hubo una coincidencia intuitiva en el significado que tenían estos productos típicos y su potencial como herramientas de fortalecimiento de la identidad regional y de su valoración por parte del público.

\section{Conclusión}

El pajarete se resiste a revelar sus secretos. Sus productores lo han mantenido en una situación de semioscuridad, dejándolo ver muy pocas veces. Solo se han revelado fragmentos de su historia; la parte central de la misma se mantiene invisible. Tal vez la explicación se encuentre en el carácter plebeyo de sus constructores: pequeños viticultores de los valles del Huasco y Elqui, que siempre lo elaboraron en pequeñas partidas, sin alcanzar nunca las dimensiones de las grandes haciendas y empresas del capitalismo moderno. Por este motivo, el pajarete ha dejado pocos rastros. A pesar de estas limitaciones se ha podido reconstruir una parte de su historia incluyendo algunos datos relevantes.

En primer lugar, se destaca la identidad del pajarete como un vino escogido; se trata de un producto especial, elaborado con esfuerzo para obtener un licor diferente; por las uvas elegidas, por el tratamiento de la uva (asoleado) y por la cuidada elaboración, el pajarete ha mantenido su prestigio como vino seleccionado. Siempre se distribuyó envasado en botellas, lo que muestra su carácter especial; y también se destaca su vínculo con un territorio específico: los valles del Huasco y el Elqui, en el Norte Chico de Chile.

El segundo dato relevante es la larga trayectoria histórica. La Aduana de Coquimbo lo registró por 
primera vez en 1790; en el siglo XIX se documentó en registros de Aduana de Chiloé y en anuncios publicitarios de la prensa gráfica de Santiago; en la centuria siguiente, el pajarete mantuvo presente en la prensa, en las guías de turismo y en los registros del INAPI. Siempre en cantidades acotadas, el pajarete ha logrado sostener su continuidad a lo largo del tiempo, hasta completar 225 años de historia. Se trata de una cifra notable para las escalas americanas.

En efecto, la contextualización del pajarete en el entorno regional, permite comprender con mayor claridad su significado. ¿Qué vino escogido puede acreditar una trayectoria comparable? En Brasil y Uruguay, la vitivinicultura es muy reciente; en Perú y Paraguay, polos vitivinícolas relevantes en los siglos XVI y XVII, no dieron continuidad a esta actividad en los siglos posteriores. En México, la experiencia de Santa María de Parras fue interesante para los siglos XVII y XVIII, y logró generar algunas diferenciaciones en la tipología de sus vinos (Corona, 2011), pero no alcanzó para generar un vino escogido. En la actual Argentina, Mendoza generó un vino escogido en el siglo XVIII, el llamado "vino a la vela", elaborado mediante crianza biológica bajo velo de flor; pero esta iniciativa solo prosperó en la primera mitad del siglo XVIII (Lacoste, 2007); después de esa fecha, desapareció. Otro caso comparable sería el vino asoleado de Cauquenes y Concepción, cuya trayectoria también fue más corta. Por lo tanto, de acuerdo al actual estado de las investigaciones sobre el tema, el pajarete sería el más antiguo vino escogido de América.

El reconocimiento como Denominación de Origen por ley en 1953 significó una protección legal, pero con escaso impacto socioeconómico.
Durante más de medio siglo, la mera existencia de esa norma jurídica, no fue suficiente para impulsar y fortalecer el desarrollo del pajarete. En todo ese tiempo, este vino se mantuvo en niveles mínimos de existencia; las escasas producciones artesanales de los viticultores del Norte Chico se mantuvieron apenas en los límites de la supervivencia, sin mayor impacto en el mercado y sin crear encadenamientos productivos regionales.

El estancamiento del pajarete se explica, en buena medida, por la ausencia en Chile, de una cultura de la valoración de las Denominaciones de Origen. Ni los mercados ni las redes comerciales ni los inversores se interesaron en el potencial que podía tener este producto. Sus posibles nichos de mercado fueron ocupados por otros productos, sin mayor identidad ni historia, como los late harvest y las imitaciones de Jerez, Oporto y similares.

Mirando hacia el futuro, las expectativas se presentan con cierto optimismo. Sobre todo porque, poco a poco, se ha comenzado a revertir la tendencia. Después de un largo ciclo de hegemonía del paradigma francés, América Latina está recuperando su confianza en sí misma, y ha comenzado a revindicar su identidad y el valor de sus creaciones originales (Sousa, 2015). En este contexto, se percibe una tendencia a revalorizar los productos típicos y Denominaciones de Origen. En este contexto, las perspectivas de productos como el pajarete, son promisorias.

\section{Agradecimientos}

Los autores agradecen al Proyecto Fondecyt 1130096 por los aportes entregados.

\section{Literatura Citada}

Abela y Sainz, E.

2008. El libro del viticultor. Primera edición: Madrid, Tipografía de Manuel G. Hernández, 1885. Edición facsimilar consultada: Editorial Maxtor, Valladolid, España. 326 p.

Aillón, E.; Kirigin, M.A.

2013. San Pedro: testigo de los tiempos. Por la ruta del Singani en Bolivia, siglos XVI-XXI. Biblioteca Nacional, Sucre, Bolivia. 398 p.

Barco, E.

2015. La configuración del sector vitivinícola en la DOCa Rioja. Análisis histórico (parte II). RIVAR, 2 (6): 25-45.

Barco, E.

2015. La configuración del sector vitivinícola en la DOCa Rioja. Análisis histórico (I). RIVAR, 2 (5): 40-63.
Barreda, F.

2001. El Chacolí santanderino en los siglos XIII al XIX. Altamira Revista del Centro de Estudios Montañeses 1, 2 y 3, (Santander, 1947). Edición facsimilar: Ed. Maxtor, Valladolid, España. 76 p.

Bennett, N.

2005. Aguardente e Vinho do Porto c. 1650-1908. GEHVID. Porto, Portugal. 253 p.

Buitrago, A.

2014. La vitivinicultura emergente en Bolivia y las oportunidades para el Singani. RIVAR, 1 (2): 87-101.

Braudel, F.

1994. Bebidas y excitantes. Alianza Cien. Madrid, España. $63 \mathrm{p}$. 
Buller, C.

2011. Vinos, aguardiente y mercado. Auge y declive de la economía del vino en los valles de Arequipa (1770-1853). Quellca. Lima, Perú. 412 p.

Castro, A.; Mujica, F.; Argandoña, F.

2015. Vinos de Pintatani y Codpa. Productos típicos en los relatos campesinos, 1847-2013. RIVAR, 2 (6): 70-86.

Castro, A.; León, A.; Cussen, F; Lacoste, P.

2016. ¡Viva la chicha nueva! La chicha en la vida popular y campesina chilena. Idesia 34 (1): 77-83.

Cortés, $\mathrm{H}$.

2005. El origen, producción y comercio del pisco chileno, 1546-1931. Universum, 20 (2): 42-81.

Couyoumdjian, J.R.

2006. Vinos en Chile desde la Independencia hasta el fin de la belle époque. Historia, 39 (1): 23-64.

Duhart, F.

2010. Los vinos andaluces en la Francia ilustrada: Contribución a la antropología del buen gusto. En: Duhart, F.; Corona, S. (eds.). Vinos de América y de Europa. Éditions Le Manuscrit. Paris, Francia, pp. 249-258.

Errázuriz Tortorelli, C.

2010. Indicaciones geográficas y Denominaciones de Origen. Propiedad intelectual en progreso. Revista Chilena de Derecho, 37 (2): 207-239.

Gil, G.; Ph. Pszczólkowski

2015. Viticultura: Fundamentos para Optimizar Producción y Calidad. Santiago, Ediciones Universidad Católica de Chile. Santiago, Chile. 319 p.

Gómez Urdáñez, J.L.

2015. El Rioja, una larga historia social y cultural. RIVAR, 2 (5): 22-39.

EFE

1945. Guía del veraneante. Ed. Ferrocarriles del Estado. Santiago, Chile. p. 302.

EFE

1956. Guía del veraneante. Ed. Ferrocarriles del Estado. EFE

Santiago, Chile. p. 360.

1959. Guía del veraneante. Ed. Ferrocarriles del Estado.

Santiago, Chile. p. 240.

Guía turística

EFE

1966. Guía turística. Ed. Ferrocarriles del Estado. Santiago, Chile. p. 146.

INUPAL

1970. Guía General de Chile. Ed. Atenas. Santiago, Chile. p. 607.

Hidalgo, J.; Sáenz, T.; Ocete, R.

2012. Vid cultivadas y silvestre en el territorio de la antigua diócesis de Valpuesta (Álava, Burgos y Cantabria, España): un acercamiento a la historia del vino Chacolí. Revista Estudios Avanzados, 18: 101-130.

Huertas, L.

2012. Cronología de la producción del vino y del pisco (Perú 1548-2010). Editorial Universitaria. Lima, Perú. 391 p.

Instituto Nacional de Propiedad Industrial (INAPI)

1934. Registro de Marcas; No 53436, 6 de Setiembre de 1934, Juan F. Terrisse, Industrial, domiciliado en Lira 180, Santiago.
Instituto Nacional de Propiedad Industrial (INAPI)

1945. Registro de Marcas; No 74825, 22 de enero de 1945, Juan F. Terisse Thebault, Industrial, domiciliado en Marín 363, Santiago.

Instituto Nacional de Propiedad Industrial (INAPI) 1946. Registro de Marcas; No 80140, 28 de octubre de 1946, Sucesión Agustín Barraza, Industrial, domiciliado en Vallenar, Serrano 1351, Santiago.

Instituto Nacional de Propiedad Industrial (INAPI). 1948. Registro de Marcas; $N^{\circ} 86419,25$ de septiembre de 1948, Sociedad Cooperativa Agrícola Control Pisquero de Elqui y Vitivinícola del Norte Ltda., Industrial, Santiago, Purísima 43.

Instituto Nacional de Propiedad Industrial (INAPI)

1951. Registro de Marcas; No 9562927 de septiembre de 1951, Evarito Guerrero Alday, Comerciante, domiciliado en Vallenar, Serrano 1006

Jiménez, D.

2014. La consolidación de la Denominación de Origen Pisco (1931): una mirada desde los debates parlamentarios y sus referentes internacionales (1901-1931). RIVAR, 1 (2): 71-86.

Lachaud-Martin, S.

2015. Le Sauternais moderne ou la conversion progressive d'espace de polyculture en vignoble (XVI-XIII siecles). RIVAR, 2 (6): 1-24.

Lacoste, P.; Castro, A.; Jiménez, D.; Soto, N.; Rendón, B.; Briones, $\mathrm{F}$.

2015. The rise and fall of Chanco cheese in Chile (1860-1930). Cien. Inv. Agr., 42 (1): 85-96.

Lacoste, P.; Soto, N.; Jiménez, D.

2014. Genesis and identity of Chanco cheese (Chile 17501860). Contribution to the study of Appellations of Origin in Latin America. Cien. Inv. Agr., 41 (3): 317-325.

Lacoste, P.; Jiménez, D.; Castro, A.; Rendón, B. y Soto, N. 2013. A binational Appellation of Origin: Pisco in Chile and Peru. Chilean journal of agricultural research, 73 (4): 424-429.

Lacoste, P.; Castro, A.; Briones, F.; Cussen, F.; Soto, N.; Rendón,

B.; Mujica, F.; Aguilera, P.; Adunka, M.; Núñez, E. y Cofré, C. Vinos típicos de Chile: ascenso y declinación del Chacolí (1810-2015). Idesia, 33 (3): 97-108.

Lacoste, P.; Duhart, F.

2010. El vino, protagonista de Dumas. Evocaciones y papeles del vino en el ciclo de los mosqueteros. En: Duhart, F.; Corona S. (eds). Vinos de América y de Europa. Éditions Le Manuscrit. París, Francia. Pp. 313-339.

Lacoste, P.

2007. Complejidad de la industria vitivinícola colonial: crianza biológica de vino (Reino de Chile, siglo XVIII). Latin American Research Review, 42 (2): 154-168.

Menadier, J.

2012. La agricultura y el progreso de Chile. Cámara Chilena de la Construcción. Santiago, Chile. 707 p.

2015. Jamón de Chiloé: itinerario histórico de un producto típico de América del Sur (siglo XVIII y XIX). Sometido a evaluación en Revista Cuadernos de Historia (Universidad de Chile)

Olmedo Valderrama, J.E.

2007. La Vendimia en el valle del Carmen. Vallenar, Atacama. Biblioteca Nacional, Colección FUCOA, Caja 47, Carpeta 203, Cuento 10. 350 p. 
Ramírez, S.; Ramírez, C.

2015. El pajarete (testimonio). En: Varios Autores. Patrimonio Vitivinícola. Aproximaciones a la cultura del vino en Chile. Ediciones Biblioteca Nacional. Santiago, Chile. pp. 82-91.

Ramos Santana, A

(2004). Vinos licorosos en las conmemoraciones españolas de entre siglos (del siglo XIX al siglo XX). Douro 17: 19-29.

Ribeiro de Almeida, A.

2010. A Autonomía Jurídica da Denominacao de Origem. Uma perspectiva transnacional. Uma garantía de qualidade. Coimbra Editora. Porto, Portugal. 1475 p.

Rivero, S.; Minnery, A.M.; Ocete, R.; López Martínez, M.A. 2001. Pajarete, historia y futuro. Douro 12: 221-227.

Rojas, M.

1987. Tratado de Viticultura y vinificación. $2^{\text {a }}$ edición, Imprenta Barcelona. Santiago, Chile. 667 p.
Rojas, M.

1950. Viticultura y vinificación. 5a edición, Nascimento, Santiago, Chile. 831 pp.

Sotomayor, J.P.

1987. Denominación de Origen: Vino Asoleado y Pajarete. I Simposio Internacional sobre Denominación de Origen de productos vitivinícolas en América Latina. La Serena, del 22 al 27 de noviembre de 1987. Santiago de Chile, SAG, tomo I: 298-313.

Sousa, A.L.

2015. Denominaciones de Origen en Brasil: su desarrollo en los últimos años considerando la jurisprudencia y los avances obtenidos por los productores. RIVAR, 2 (5): 1-21.

Unwin, $\mathrm{T}$.

2001. El vino y la viña. Geografía histórica de la viticultura y el comercio del vino. Tusquets. Barcelona, España. 529 p. 
